\title{
Effects of abiotic elicitors on the production of bioactive flavonols in Emilia sonchifolia
}

\author{
Mohan RAJI, Zhong CHEN* \\ Natural Sciences and Science Education, National Institute of Education, Nanyang Technological University, Singapore 637616, Singapore \\ *Correspondence: zhong.chen@nie.edu.sg \\ https://doi.org/10.37175/stemedicine.v1i2.33
}

\begin{abstract}
Background: The usage of plants as a source of medicine begins with the isolation of active biocompounds which are responsible for their therapeutic action. Research on flavonols has flourished in the last decade, fuelled by the recognized importance of natural antioxidants on health.

Methods: Based on the meagre information reported on the effect of stress treatment on the production of flavonol metabolites, the current research attempted to investigate if heat (one-day for 6 hours at $45^{\circ} \mathrm{C}$ ) and drought stress (one week) could be used to enhance the production of three flavonols, including rutin, quercetin and kaempferol, in the tropical medicinal plant Emilia sonchifolia. The study focused on a novel elicitation approach to improve the therapeutic value of medicinal plants.

Results: The increment in the antioxidant levels of Emilia sonchifolia was attributed to the increased accumulation of the three flavonols and total flavonoid content with strong scavenging ability against free radicals.

Conclusion: Short-term heat stress and moderate water deficit proved as effective strategies to increase the rutin, quercetin and kaempferol contents in Emilia sonchifolia.
\end{abstract}

Keywords: Lilac tassel flower · Antioxidant activity $\cdot$ Rutin $\cdot$ Quercetin $\cdot$ Kaempferol

\section{Introduction}

Tropical countries are home to a variety of different medicinally important plants, due to the presence of bioactive compounds which are secondary plant metabolites. The latest interest in secondary plant metabolites lies in obtaining new sources of compounds that have promising potential to function in therapeutic systems $(1,2)$. Medicinal plants are usually assessed based on their therapeutic value. The therapeutic effects of these metabolites have been associated with their antioxidant activity, which could be the scientific basis of traditional herbal-based treatment of diseases (3). The isolation and characterization of drugs are based on the pharmacologically active plant secondary metabolites (4). Root, bark, stem and leaves are the primary sources of different and unique secondary metabolites in plants, of which the most widely distributed bioactive groups are

Received: Dec 30, 2019; Accepted: Mar 8, 2020.

(C) The Author(s). 2019 This is an Open Access article distributed under the terms of the Creative Commons License (http://creativecommons.org/licenses/by/4.0/) which permits unrestricted use, distribution, and reproduction in any medium or format, provided the original work is properly cited. flavonoids that exist both in free state and as glycosides (5). Flavonols belong to the most abundant group of flavonoids, with most prominent antioxidant activity by possessing the chemical structure of 3-hydroxyflavone skeleton (6). The presence of flavonols in the form of fruits (quercetin in blueberries, strawberries), leafy green vegetables, onions and beverages (tea and red wine) is inversely associated with the incidence of breast cancer, diabetes, heart disease and neurodegenerative diseases including Alzheimer's. Moreover, medicinal plants such as Moringa oleifera, Azadirachta indica, Aloe barbadensis, Ginkgo biloba and Calendula officinalis are reported to contain higher level of flavonols (7). Flavonols such as rutin, quercetin and kaempferol (Figure 1) are unique reactive oxygen species (ROS) scavengers with antiplatelet, anti-neural, cancer preventive, antioxidant and antiinflammatory properties $(7,8)$. Consequently, they possess beneficial pharmaceutical, nutritional and therapeutic effects in humans. Rutin is usually recommended for treatment of haemorrhoids or internal bleeding, varicose veins and reducing the risk of arteriosclerosis (9). Quercetin could contribute significantly 
to the antioxidant defenses present in the blood and plasma as it is only slowly eliminated in humans (10). It is a lipid peroxidation inhibitor and reduces oxidative stress produced as a result of chronic diseases. Among the three flavonols, quercetin exhibits a wide range of biological activities and therapeutic applications $(11,12)$. Kaempferol is responsible for decreasing thrombin that prevents clot formation and inhibits blood clotting (13). Due to its anti-thrombotic property, it has the potential to serve as a therapeutic agent for cardiovascular patients. In plants, flavonol metabolism dates back during the evolution of terrestrial plants mostly in mosses and liverworts, and it has been reported to have relevant function in the responsive mechanism of plants under stressful conditions (14). They respond to abiotic stresses by increasing their production and detoxifying the free radicals through donation of hydrogen atom from the hydroxyl moiety thereby rendering tolerance (15).

Indeed, the exploitation of more medicinal plants is demanding due to the health hazards associated with the use of synthetic drugs. Even though the potential of medicinal plants are boundless, there are many challenges for the large scale utilization in pharmaceutics (16). Among them are the lack of reproducibility due to the variation in secondary metabolites and the limited production of metabolites (less than $1 \%$ dry weight). In medicinal plants, environmental conditions regulate the production of these complex active constituents, and their type and quantity of metabolites are often determined by the changing environmental conditions (17). When wild plants are procured and cultivated under optimal growing conditions without exposure to natural stressors, the content and therapeutic activity of secondary metabolites are reduced (18). The production of secondary metabolites should be increased to acquire maximum medicinal and nutritive values. Heat and drought are abiotic elicitors that stimulate stress responses in plants and increase the amount of secondary metabolites produced (19). This strategy helps to induce the desired chemical response by establishing a relationship between phytochemistry and plant stress. This technique is known as elicitation which not only increases the therapeutic activity of medicinal plants but also enhances the health benefits of edible plants that are consumed as food.
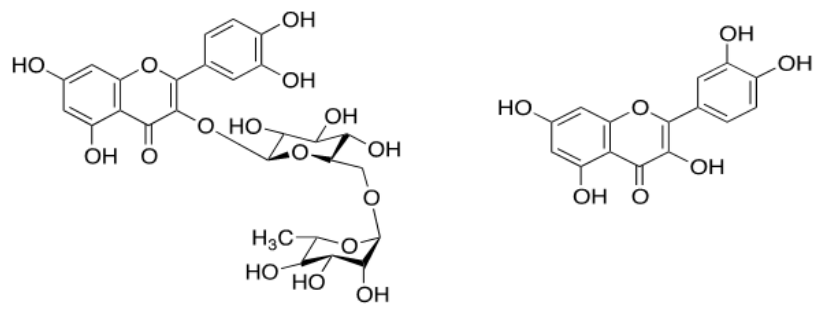

Comparatively, little information has been gained in recent years regarding the methods to improve the therapeutic activity in whole medicinal plants. There is also not much updated knowledge on the antioxidant metabolism under heat and drought stress in medicinal plants. It seems necessary to study the connection between medicinal plants and abiotic stresses. Therefore, we aimed to test the medicinal plant Emilia sonchifolia (E. sonchifolia) for its antioxidant activity and study its abiotic stress response on flavonol metabolite production through the elicitation process. Under thermal stress flavonols could be either increased, unaffected or decreased depending upon the degree/intensity, duration of the temperature, flavonoid structure and finally the plant species. The accumulation of flavonols under water deficit conditions could be attributed to the severity of drought, growth stage of the plant and the stress tolerant level inherent in each species. To date, there hasn't been sufficient data to conclude on the impact of temperature or drought on flavonols. The present work also aimed to understand the adaptability of flavonols in response to environmental stresses and find out effective methods for their natural production. The choice of investigated medicinal plant depends on four reasons: firstly, availability as it is a locally available and easily grown weed plant. Secondly, it is a good source of flavonols (20) and widely used in traditional medicine. Thirdly, it is tolerant to abiotic stresses like heat and drought. Fourthly, no elicitation studies have been reported in this plant species.

E. sonchifolia belongs to family Asteraceae and is known by the names 'Cupid's shaving brush' and 'Lilac tassel flower'. It is listed in the Indian system of Ayurveda and traditional Chinese medicine (TCM) (21). It is widely present in tropical regions of India, China and Southeast Asia as weeds in grassy fields, crop fields and along roadsides. The leaves of E. sonchifolia proficiently treat night blindness, wounds and abscesses, roundworm infestations, snake bites, burns, cough, sore ears, fever and bronchitis, while the roots are used for treating diarrhoea (22). Various studies also have documented the pharmacological activities of E. sonchifolia extracts against microbials, inflammation (23), cataract (24), oxidation (25), diabetes (26) and virus (27).

(C)<smiles>O=c1c(O)c(-c2ccc(O)cc2)oc2cc(O)cc(O)c12</smiles>

Figure 1: Chemical structures of (A) rutin, (B) quercetin, and (C) kaempferol. 


\section{Materials and Methods}

\subsection{Plant Materials}

The tropical medicinal plant E. sonchifolia (3-monthold) was used for the study. The seeds of E. sonchifolia were obtained from Molecular Genetics Lab at National Institute of Education (NIE), Singapore. The seedlings of uniform size were transplanted to black polythene bags $(21 \times 12 \mathrm{~cm})$ containing a mixture of peat moss and vermiculite $(3: 1)$. The plants were grown under natural light conditions of photosynthetic photon flux density (PPFD) $300 \mu \mathrm{mol} \mathrm{m} \mathrm{m}^{-2}$ in the NIE greenhouse, watered once daily for three months.

\subsection{Experimental conditions}

The experiment was conducted at NIE. Plants grown in optimal temperature and watered regularly were used as reference or control for each treatment. For the heat treatment, five replicates of the plant were transferred to an incubator with white fluorescent light of PPFD $50 \mu \mathrm{mol} \mathrm{m} \mathrm{m}^{-2}$ and exposed to heat stress for 6 hours continuously in a single day under temperature stress set at $45^{\circ} \mathrm{C}$. For the drought treatment, another batch of five replicates of the plant was subjected to a continuous water deficit for 7 days. The drought stress experiment was conducted in the NIE greenhouse. The leaf samples for analysis were harvested at time 0 (control) and at the end of respective treatments.

\subsection{Determination of relative water content (RWC) in drought-stressed plants}

The leaves of E. sonchifolia were harvested and immediately transferred to a sealed plastic bag to avoid moisture loss. The sample leaves were cut into small pieces and immediately weighed with an analytical balance to record the fresh weight (FW). The weighed leaves were then submerged in water for 24 hours in the dark to record their saturated weight (SW). Subsequently, the samples were wrapped in aluminum foil and dried in an oven at $80{ }^{\circ} \mathrm{C}$ for 4 days. The dry weight (DW) of the leaves was recorded. The RWC of samples was calculated using the formula: $\mathrm{RWC}=(\mathrm{FW}-\mathrm{DW}) /(\mathrm{SW}-\mathrm{DW}) \times 100 \%(28)$.

\subsection{DAB staining for the qualitative detection of ROS $\left(\mathrm{H}_{2} \mathrm{O}_{2}\right)$ under the influence of heat and drought stress treatments}

The DAB staining solution of concentration $1 \mathrm{mg} / \mathrm{ml}$ was prepared freshly in a $50 \mathrm{ml}$ falcon tube according to the standard protocol (29). Harvested leaves of E. sonchifolia were placed inside the petri plates and covered with aluminium foil as DAB is light sensitive. $1 \mathrm{mg} / \mathrm{ml} \mathrm{DAB}$ staining solution was added to keep the leaves fully immersed. They were then vacuum infiltrated for 15 minutes. The treated leaves were incubated inside a standard laboratory shaker for 8 hours until the leaves were thoroughly infiltrated with the staining solution at $100 \mathrm{rpm}$. Following the incubation, the DAB solution was replaced with $80 \%(\mathrm{v} / \mathrm{v})$ ethanol. The plates were carefully placed in $80{ }^{\circ} \mathrm{C}$ water bath for 15 minutes to remove chlorophyll. DAB-stained leaves were visualized as brown colour. It was then stored in a solution of ethanol:acetic acid:glycerol in a ratio of $3: 1: 1$ until photographed.

\subsection{Preparation of Extracts}

The air-dried leaves were subjected to freeze-drying or lyophilization to remove the moisture content. The thoroughly dried leaves were then ground into a fine powder using a pestle and mortar. Using $5 \mathrm{ml}$ of extracting solvent $80 \%$ (v/v) methanol-water, approximately $200 \mathrm{mg}$ of leaf powder was extracted using an ultrasonic cleaner (37 kHz, 150W, S70 Elmasonic Germany) for 30 minutes at room temperature. Following the extraction, the mixture was centrifuged at $3500 \mathrm{rpm}, 25^{\circ} \mathrm{C}$ for 5 minutes. The supernatant was recovered and filtered using $0.45 \mu \mathrm{m}$ syringe filters, followed by solid phase extraction (SPE) using the Sep-Pak C18 cartridge. To start the process, the cartridge was saturated with methanol. Around $400 \mu \mathrm{l}$ of the plant sample was then added into the cartridge with the help of vacuum pump, followed by eluting with $50 \mathrm{ml}$ of methanol solvent and then rotary evaporated. The residue was then re-dissolved in $1 \mathrm{ml} \mathrm{LC} / \mathrm{MS}$ grade methanol, before being injected to the column, Following the modified method from Neves, Stringheta (30).

\subsection{LC-MS analysis}

The detection of three flavonol compounds was performed using an Agilent 1100 series (Agilent Technologies, CA, USA) liquid chromatography coupled to ion trap mass spectrometer (LC/MSD Trap XCT) with ESI interface. The mobile phase was degassed ultrasonically following a gradient program using solvent A: $0.1 \%$ formic acid (FA) in water and solvent B: $0.1 \% \mathrm{FA}$ in methanol. The flow rate used was $0.7 \mathrm{ml} / \mathrm{min}$ while $15 \mu \mathrm{l}$ of sample was injected into the Phenomenex Kinetex C18 reverse phase column $(\varnothing 100 \mathrm{~mm} \times 4.6 \mathrm{~mm} \times 2.6 \mu \mathrm{m})$. The column temperature was maintained at $30{ }^{\circ} \mathrm{C}$. The samples were passed through a $0.45 \mu \mathrm{m}$ syringe filter before being injected into a column. The system was run with the following elution program: $18 \%$ to $95 \%$ B for 31 minutes, then hold at $95 \%$ B for 3 minutes before re-conditioning back to the initial composition in 1 minute. Mass spectra of analyses were performed with the scan range of $\mathrm{m} / \mathrm{z}$ $200-650$ in a negative ion mode. The mass spectrometric parameters including nebulizing gas pressure, capillary voltage, dry gas temperature and flow rate were set to $40 \mathrm{psi}, 4.5 \mathrm{kV}, 350{ }^{\circ} \mathrm{C}$ and $10 \mathrm{~L} / \mathrm{min}$, and kept constant throughout the analysis. LC/MS Chemstation software was used for data analysis. The detection of the eluted peaks of rutin, quercetin and kaempferol was performed at $360 \mathrm{~nm}$. The retention time obtained based on triplicates for rutin, quercetin and kaempferol were 27.2, 29.2 and 30.2 minutes, respectively.

\subsection{Quantification of total flavonoids using spectrophotometry}

The total flavonoid content (TFC) was determined spectrophotometrically following the aluminium 
chloride $\left(\mathrm{AlCl}_{3}\right)$ method (31). The flavonol standard rutin $(1 \mathrm{mg} / \mathrm{ml}$ ) prepared in $80 \%$ methanol was used to generate a standard curve with four concentrations of $0.0125,0.025$, 0.05 , and $0.1 \mathrm{mg} / \mathrm{ml}$, respectively. $0.5 \mathrm{ml}$ of dried plant extract from SPE was mixed with $1.5 \mathrm{ml}$ of $80 \%$ methanol, $0.1 \mathrm{ml}$ of $10 \%$ aqueous dilution of $\mathrm{AlCl}_{3}, 0.1 \mathrm{~mL}$ of $1 \mathrm{M}$ potassium acetate and finally with $2.8 \mathrm{ml}$ of distilled water. The mixed contents in each tube were allowed to incubate at $22{ }^{\circ} \mathrm{C}$ for 30 minutes. The blank was prepared for each sample which consisted of all reagents except $\mathrm{AlCl}_{3}$. The absorbance was measured at $415 \mathrm{~nm}$. The total content of flavonoids in plant extracts in rutin equivalent was calculated by the following equation: $\mathrm{C}=(\mathrm{c} \times \mathrm{v}) / \mathrm{m}$. $\mathrm{C}=$ Total content of flavonoid compounds, $\mathrm{mgg}^{-1} \mathrm{DW}$, in rutin equivalent (RE), $\mathrm{c}=$ Concentration of rutin established from the calibration curve, $\mathrm{mgg}^{-1} \mathrm{DW}, \mathrm{v}=$ Volume of extract, $\mathrm{ml}, \mathrm{m}=$ Mass of extract, gm.

\subsection{Measurement of antioxidant activity using DPPH method}

Different concentrations of leaf extracts $(1 \mathrm{mg} / \mathrm{ml})$ of E. sonchifolia were prepared in methanol equivalent to 50, 100, 200 and 400 ppm. 80\% methanol was used as a solvent. Ascorbic acid was used as the positive control. A stock solution of $0.06 \mathrm{mM}$ methanolic solution of DPPH was prepared by weighing $5.91 \mathrm{mg}$ of DPPH powder in an Eppendorf tube containing $1 \mathrm{ml}$ of methanol. The tube was centrifuged at $3000 \mathrm{rpm}$ and then transferred to $250 \mathrm{ml}$ volumetric flask, with the volume of methanol adjusted accordingly. $5 \mathrm{ml}$ of $0.06 \mathrm{mM}$ solution of DPPH was mixed with $0.5 \mathrm{ml}$ of plant samples and standard solutions, separately. These solution mixtures were kept in a dark place for 30 minutes, and the optical density was measured at $517 \mathrm{~nm}$. The blank control was prepared for each sample which consisted of all reagents except the tested extracts. Each analysis was done in triplicate. The radical scavenging of the methanolic extract of $E$. sonchifolia leaves was calculated from the formula: Percentage radicalscavenging activity $=(\mathrm{OD}$ control $-\mathrm{OD}$ sample $/ \mathrm{OD}$ control $) \times 100$. OD control $=$ Absorbance of the control, OD sample $=$ Absorbance of the tested plant extract.

\subsection{Statistical analysis}

ANOVA (one-way analysis of variance) was performed to test for the significant difference between optimal and the treated conditions. The Dunnett's test was also used for multiple comparisons and to determine differences among treatment means at significance levels of $\mathrm{P}<0.05$. The Pearson's correlation coefficient ( $r$ ) was calculated (between +1 and -1 ) using the SPSS software (version 16; SPSS Inc, Chicago, USA) that measures the strength of linear correlation between two variables. The Origin Pro software was used to plot the graph. The Graphpad Prism 8 was used to plot the graph for antioxidant studies.

\section{Results and Discussion}

\subsection{RWC in drought-stressed plant leaves}

The plant E. sonchifolia at optimal conditions recorded leaf RWC value of $97.5 \%$. At the end of water deficit stress, RWC was reduced to $80 \%$ (Figure 2). The RWC of E. sonchifolia tended to decrease slightly with increased water stress level. However, the percentage drop of $18 \%$ suggested that the stressed leaves of the plant experienced a slow rate of water loss that developed acclimation to drought stress. The results showed that RWC was an indicator of water deficit stress, consistent with previous observation in Stellaria dichotoma (32).

\subsection{DAB staining for $\operatorname{ROS}\left(\mathrm{H}_{2} \mathrm{O}_{2}\right)$ under heat and drought stress treatments}

The DAB-stained leaves of E. sonchifolia were visually detected (Figure 3). The brown colour developed on the leaves directly correlated with $\mathrm{H}_{2} \mathrm{O}_{2}$ accumulation, and it was evident that the leaves of stressed plants appeared more brownish and hence, accumulated more $\mathrm{H}_{2} \mathrm{O}_{2}$ than the leaves of unstressed plants. The appearance of dark spots was more visible in heat-stressed (Figure 3C) and drought-stressed (Figure 3B) plants, with no dark spots accumulated in control plants. The pattern observed in DAB staining suggested that the stressed plants accumulated more ROS. The data indicated that stress developed in all treated plants at the time of biochemical evaluations, and the visibility of ROS depended on the stress tolerance of the species.

\subsection{Detection of flavonols rutin, quercetin and kaempferol using LC-MS}

Using LC-MS method, the three flavonol compounds in E. sonchifolia were confirmed by comparing their respective characteristic fragmentation patterns with the corresponding flavonol standards at a specific retention time (Figures 4-5). The distinctive fragmentationpattern of each flavonol standard was studied using both alternating positive $[\mathrm{M}+\mathrm{H}]^{+}$and negative $[\mathrm{M}-\mathrm{H}]^{-}$ion ESIMS. The negative ion mode was selected for the detection

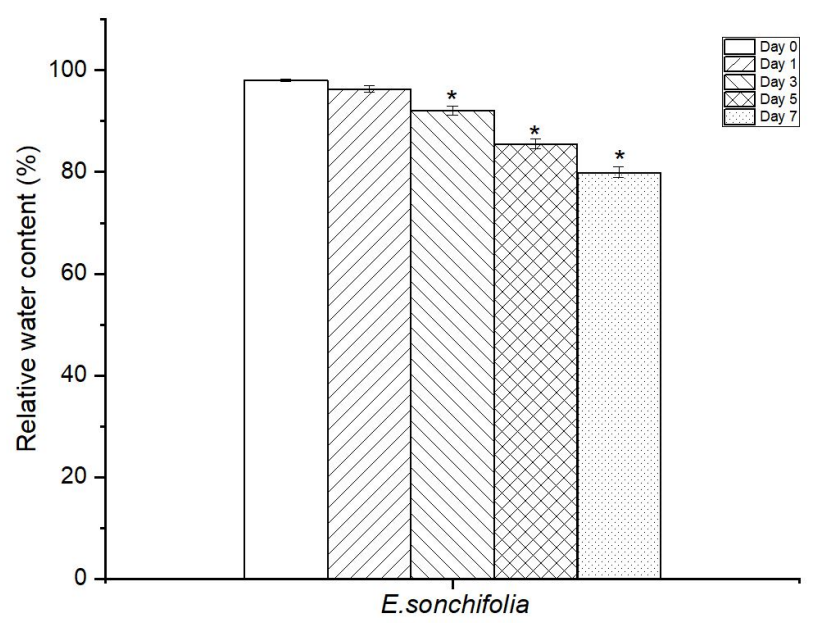

Figure 2. RWC of E. sonchifolia leaves during drought stress. The height of each bar and the error bar show the mean and standard deviation from 5 replicates. The column with single asterisk $\left({ }^{*}\right)$ adhered indicates significant differences $(P<0.05)$ as compared with day 0 , determined by Dunnett's test. 
of three flavonols as these compounds were more stable as deprotonated adducts. Furthermore, the deprotonated ions (precursor ions) of rutin, quercetin and kaempferol were detected from the methanolic extracts of leaves of each plant species that were subjected to optimal and stressed conditions (via heat and drought) at retention time 27.2, 29.2, and, 30.2, respectively. The deprotonated ions detected for rutin, quercetin and kaempferol were $m / z 609.2[\mathrm{M}-\mathrm{H}]^{-}, m / z 301$ [M-H] $^{-}, m / z 285$ [M-H] , respectively (33). The $\mathrm{m} / \mathrm{z}$ of each compound was compared with previous data analysis, including rutin (34, $35)$, quercetin $(35,36)$ and kaempferol $(36,37)$. The MS analyses of rutin, quercetin and kaempferol in $E$. sonchifolia were represented in Figures 6-8. The data of ESI-MS analysis were summarized in Table 1.

The LC-MS analysis was carried out in E. sonchifolia to evaluate the flavonol contents under normal and stressed conditions (heat and drought) and to validate the influence of stress level on the bioactive metabolites. In non-treated E. sonchifolia plants, the rutin content was observed in higher intensity than quercetin and kaempferol (Table 1). In heat-stressed and water deficit E. sonchifolia plants, the relative intensity of rutin was higher by 5.3 -fold and 4-fold, respectively than control. Furthermore, the relative intensity of quercetin in heat-stressed ones was higher by 4 -fold. Similarly, an increasing trend of quercetin was followed in drought-stressed plants with 3.3-fold higher than control. The relative intensity of kaempferol in heat, drought treated plants was higher by 3.4 -fold and 2-fold, respectively than control (Table $\mathbf{1}$ ).

\subsection{Total flavonoid content (TFC)}

The TFC of E. sonchifolia plants under heat, drought and optimal conditions was shown in Table 2. Among the stressed and optimal E. sonchifolia plants, highest TFC was detected in heat-stressed samples $(8.66 \pm$ $0.73 \mathrm{mgREg}-1 \mathrm{DW})$, followed by drought-stressed
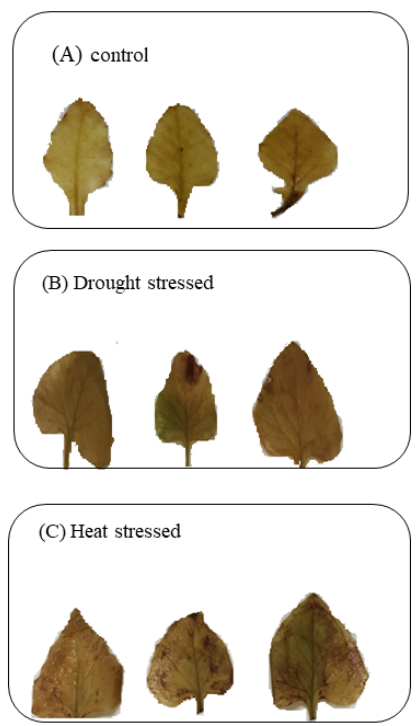

Figure 3. DAB-stained leaves of $E$. sonchifolia (3-month old). (A) control plants, (B) drought-stressed plants (1 week), and (C) heat-stressed plants $\left(45^{\circ} \mathrm{C}\right.$ for 6 hours in a day).

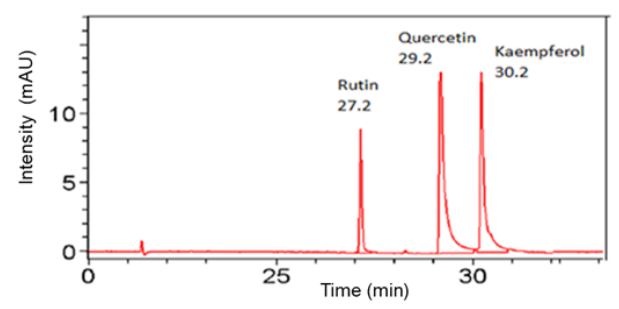

Figure 4. HPLC-UV chromatogram of flavonol standards rutin, quercetin, and kaempferol (10 ppm) with the respective retention times detected at $360 \mathrm{~nm}$.

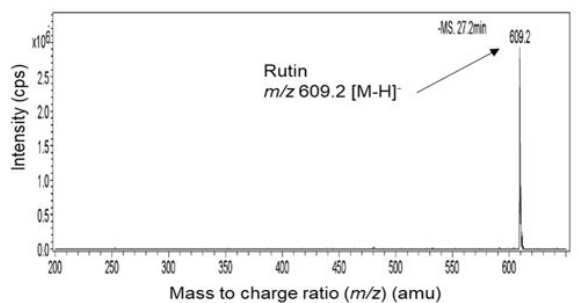

(B)

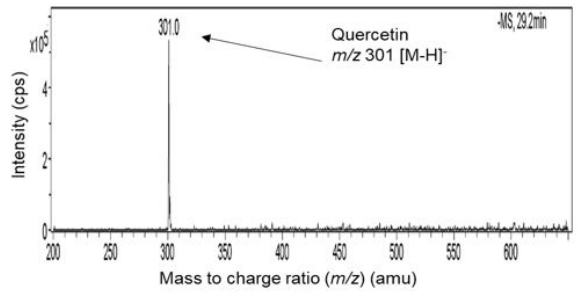

(C)

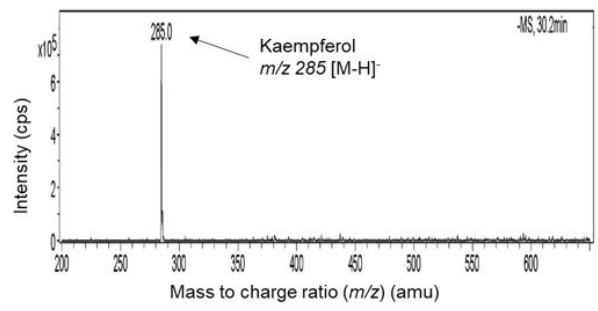

Figures 5 (A-C) Indicates the ESI-MS analysis of the mass spectra fragmentation patterns of the flavonol standards rutin, quercetin, and kaempferol with $\mathrm{x}$-axis of mass to charge ratio $(\mathrm{m} / \mathrm{z})(\mathrm{amu})$ and $\mathrm{y}$-axis indicated intensity or the ion abundance (cps). The deprotonated ions detected for rutin, quercetin and

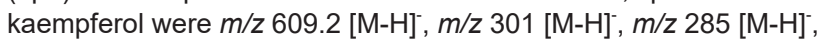
respectively at respective retention times.

$(6.01 \pm 0.85 \mathrm{mgREg}-1 \mathrm{DW})$ and then control $(3.52 \pm$ $0.84 \mathrm{mgREg}-1 \mathrm{DW})$. The data indicated that heat and drought stress enhanced the TFC in all treated plants (per gm dry weight of leaf material) compared to control plants. A notable fold change of TFC was observed in heat-stressed E. sonchifolia (1.5-fold increase). An investigation revealed that apart from the increase in flavonols, drought stress also stimulated the production of other flavonoids and hence influenced the TFC (38). Water stress is known to augment the TFC in Chrysanthemum morifolium as compared to normal (39). Xiaolu, Jie showed an increase in TFC in stems of Dendrobium moniliforme after 5 days of drought stress (40). In conclusion, quercetin, rutin and kaempferol were 
(A)

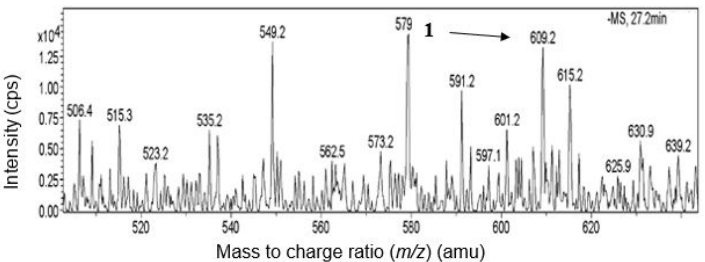

(B)

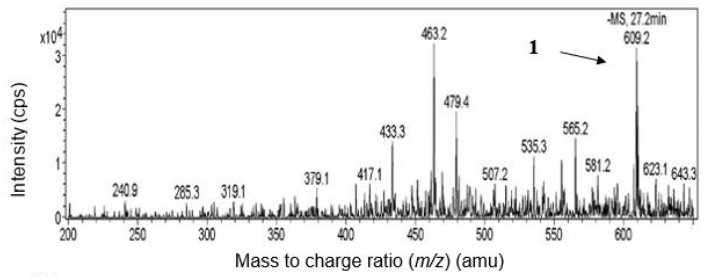

(C)

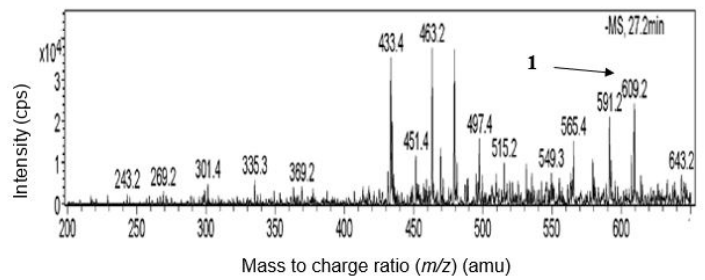

Figure 6. ESI-MS analysis of rutin in $\boldsymbol{E}$. sonchifolia. 1. rutin, with $\mathrm{m} / \mathrm{z}$ $609.2[\mathrm{M}-\mathrm{H}]$ ], indicated above at retention time 27.2. (A) control plants, (B) heat-stressed plants, and $(\mathrm{C})$ drought-stressed plants.

(A)
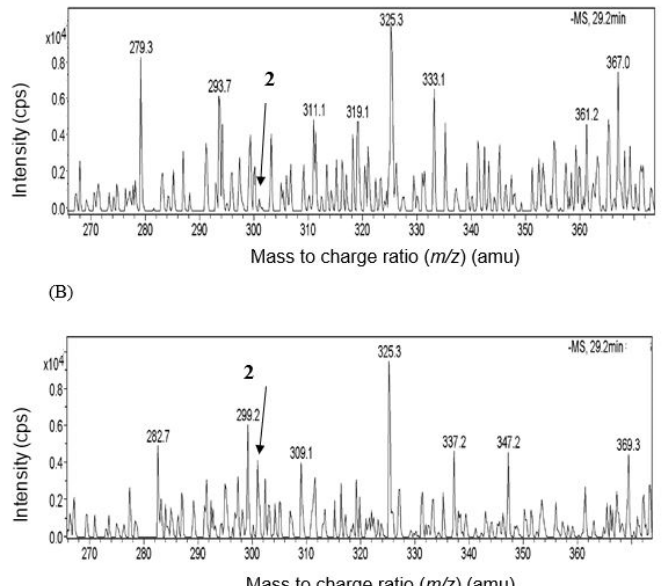

(C)

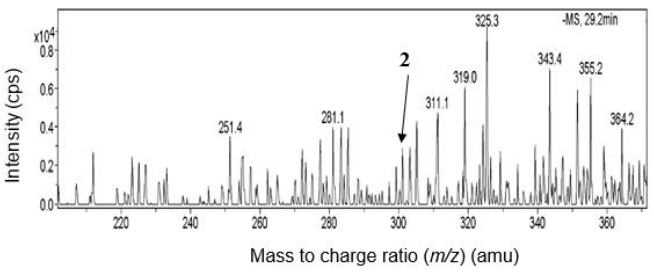

Figure 7. ESI-MS analysis of quercetin in E. sonchifolia. 2. quercetin, with $\mathrm{m} / \mathrm{z} 301[\mathrm{M}-\mathrm{H}]$, indicated above at retention time 29.2. (A) control plants, (B) heat-stressed plants, and (C) drought-stressed plants.

found to increase in stressed E. sonchifolia plants compared to the control ones, and the abiotic stresses such as drought and heat had a significant impact on the three flavonol metabolites as evident from their increasing trends. The variation in metabolite contents is due to the growth conditions, the difference in genotypes and the plant stress tolerance (41). In plants grown under optimal growing conditions, the intensity of natural stressors on the plant is lower compared to the wild plants, and the content of secondary metabolites is therefore reduced, leading to decreased therapeutic activity (18). In the study, optimal E. sonchifolia plants grown under greenhouse condition had lesser TFC than stressed plants (Table 2). As stated by Agati, Azzarello, A. thaliana grown under low light irradiance (less than $200 \mu \mathrm{mol} \mathrm{m} \mathrm{m}^{-2}$ ) was unable to stimulate the biosynthesis of quercetin, unless triggered by temperature and high light (42). In E. sonchifolia plants, rutin and quercetin increased under water deficit conditions (Table 1). The result was in agreement with the report of Nacif de Abreu and Mazzafera (43). Another study by Hodaei, Rahimmalek demonstrated that drought stress for 3 days stimulated the synthesis of rutin and quercetin in "Taraneh" cultivar of Chrysanthemum morifoilum plant (39). However, prolonged drought stress for 7 days was accompanied by a decrease in quercetin content while an increase in rutin. In another study of drought stress in two related species of hawthorn, Kirakosyan, Kaufman revealed that quercetin increased in Crataegus monogyna and decreased in Crataegus laevigata whereas rutin increased in both species (38). Rutin is a glycoside that is composed of aglycone quercetin and disaccharide rutinose (Figure 1A). Although rutin is derived from quercetin with the inclusion of rhamnoside residue in the third position,there are variations among the compounds even in related
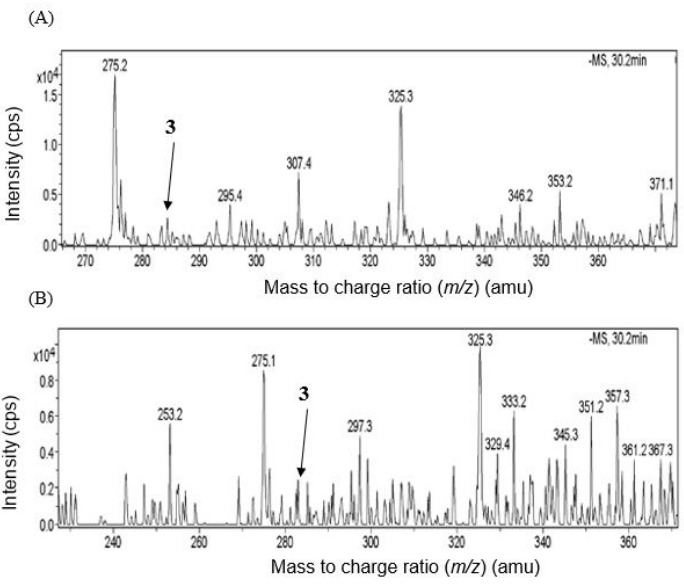

(C)

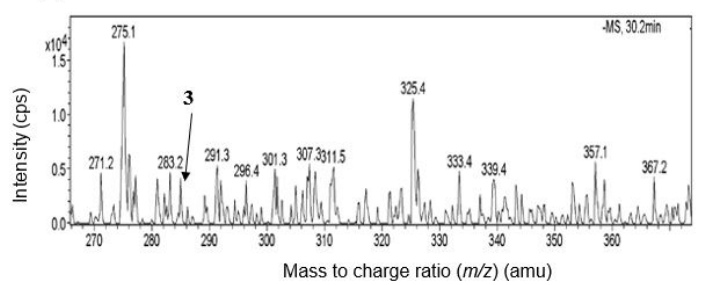

Figure 8. ESI-MS analysis of kaempferol in E. sonchifolia. 3 kaempferol, with $m / z 285[\mathrm{M}-\mathrm{H}]$, indicated above at retention time 30.2. (A) control plants, (B) heat-stressed plants, and (C) drought-stressed plants. 
species. Quercetin is O-glycosylated by rhamnose units at $\mathrm{C}_{3}$ position to form quercetin-3-O-rutinoside (Figure 1A and Figure 1B). It is clear from the studies that flavonols are mostly glycosylated in the majority of tissues to favour their storage and transport and even to protect the $\mathrm{OH}$ group from oxidation (44). In the study, it is evident that during heat and drought stress, rutin was dominated likely due to the induced rhamnosylation process that resulted in the conjugation of rhamnose to aglycone quercetin forming rutin to attain stability and tolerance against stress conditions. According to Le Roy, Huss, the pile-up of flavonol glycosides acted as a reserve of flavonols that could be utilized at any time under stress conditions like UV (44). Hectors, Van Oevelen emphasized on the role of rhamnosylated quercetin and kaempferol glycosides against UV stress in A. thaliana (45). According to the study by Nacif de Abreu and Mazzafera, although temperature stresses negatively affected the plant growth including reduced photosynthetic rate, lower biomass and premature leaf senescence, these thermal stresses significantly increased the concentration of rutin by 3-fold at $17{ }^{\circ} \mathrm{C}$, and 7 -fold at $36^{\circ} \mathrm{C}$ and also 4-fold during drought stress (43). Moreover, many authors considered the positive response of metabolites as a means to improve product quality in medicinal plants (46).

\subsection{Antioxidant activity in $E$. sonchifolia leaf extracts}

The antioxidant activity of E. sonchifolia plants was examined using the DPPH method. Figure 9 shows the radical scavenging activity of $E$. sonchifolia extracts at increasing concentration. The maximum percentage inhibition was observed in heat-stressed plants, followed by drought-stressed and finally the optimal ones, i.e., the stressed plant extracts exhibited higher antioxidant activity. Among the various concentrations of E. sonchifolia extracts tested, the concentration of $400 \mu \mathrm{g} / \mathrm{ml}$ showed the highest scavenging activity of $95.5 \%$, and it was observed in extracts of heat-stressed E. sonchifolia samples. Meanwhile ascorbic acid at the same concentration showed $98.57 \%$ which showed close similarity to each other. The $\mathrm{IC}_{50}$ values, which correspond to the plant extract concentration required to scavenge $50 \%$ of the free radical, of E. sonchifolia were calculated from the percentage scavenging curve plotted against the concentration (Table 3). The $\mathrm{IC}_{50}$ value was inversely related to the antioxidant activity. The lesser $\mathrm{IC}_{50}$ value and higher radical scavenging activity indicated higher antioxidant activity. The plant extract that exhibited the highest reducing capacity was the heat-stressed E. sonchifolia extracts as determined by the neutralization of DPPH with the $\mathrm{IC}_{50}$ value of $40.65 \mu \mathrm{g} / \mathrm{ml}$. Also, the highest TFC was found in heat-stressed $E$. sonchifolia extracts.

The results in Figure 9 indicated that the $80 \%$ methanolic extracts of E. sonchifolia showed strong radical scavenging activity compared to vitamin $C$. The medicinal plant E. sonchifolia has been found to be promising in terms of antioxidant activity, hence the plant can be considered as a source of natural antioxidants for medicinal uses. The superiority demonstrated by E. sonchifolia extracts in scavenging free radicals therefore could be attributed to the presence of flavonoid metabolites. According to Nakabayashi, YonekuraSakakibara, quercetin and its glycosides containing more hydroxyl group exhibited more antioxidant activity than kaempferol (47). Therefore, the higher rutin and quercetin contents in E. sonchifolia plants might contribute to the enhanced antioxidant activity of E. sonchifolia plants, which counterbalanced the negative factors and protected plants against oxidative damage. The visible signs of stress were prominent in $E$. sonchifolia (Figure 3), indicating that these plants were more exposed to severe oxidative stress surpassing their defence mechanism during their initial encounter with ROS. Since ROS generation is an indication of stress, it has been postulated that biosynthesis of flavonoids is triggered as a supplementary defense mechanism, aimed at detoxifying ROS (48). Under severe stress conditions, secondary flavonoid metabolites function as a secondary or auxiliary scavenging system in plants, complementing the inefficient enzymatic defense mechanism in cells (42).

Table 1. LC-MS analysis of rutin, quercetin, and kaempferol in E. sonchifolia under heat-stressed and drought-stressed conditions.

\begin{tabular}{|c|c|c|c|c|c|c|c|}
\hline Species & Condition & Compounds & Intensity(cps) & RT & Molecular formula & Calculated $[\mathrm{M}-\mathrm{H}]^{-}$ & Observed $[\mathrm{M}-\mathrm{H}]^{-}$ \\
\hline \multirow{9}{*}{ E. sonchifolia } & Control & \multirow{3}{*}{ Rutin } & $7.5 \times 10^{3}$ & \multirow{3}{*}{27.2} & \multirow{3}{*}{$\mathrm{C}_{27} \mathrm{H}_{30} \mathrm{O}_{16}$} & \multirow{3}{*}{609.5} & \multirow{3}{*}{609.2} \\
\hline & Heat & & $4 \times 10^{4}$ & & & & \\
\hline & Drought & & $3 \times 10^{4}$ & & & & \\
\hline & Control & \multirow{3}{*}{ Quercetin } & $4.5 \times 10^{2}$ & \multirow{3}{*}{29.2} & \multirow{3}{*}{$\mathrm{C}_{15} \mathrm{H}_{10} \mathrm{O}_{7}$} & \multirow{3}{*}{301.2} & \multirow{3}{*}{301} \\
\hline & Heat & & $2 \times 10^{3}$ & & & & \\
\hline & Drought & & $1.5 \times 10^{3}$ & & & & \\
\hline & Control & \multirow{3}{*}{ Kaempferol } & $1.2 \times 10^{3}$ & \multirow{3}{*}{30.2} & \multirow{3}{*}{$\mathrm{C}_{15} \mathrm{H}_{10} \mathrm{O}_{6}$} & \multirow{3}{*}{285.2} & \multirow{3}{*}{285} \\
\hline & Heat & & $4.1 \times 10^{3}$ & & & & \\
\hline & Drought & & $2.3 \times 10^{3}$ & & & & \\
\hline
\end{tabular}


Therefore, the stress conditions might trigger the production of more flavonoids, supporting the results obtained in this study. The results indicated that the three flavonols (Table 1), and the TFC (Table 2) were higher in stressed E. sonchifolia plants than other plants.

Flavonoids are excellent ROS scavengers, including quercetin and its glycosides. The stable glycosylated flavonol rutin responded positively to both heat and drought stresses regardless of the species, whereas the metabolites quercetin and kaempferol responded differently to two types of stresses, indicating the role

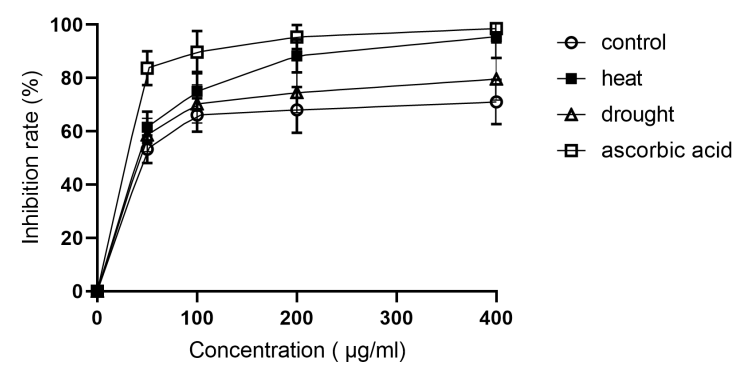

Figure 9. DPPH scavenging activity of methanolic extracts of $E$. sonchifolia with ascorbic acid. Data were represented as mean \pm standard deviation of triplicate experiments.

of the three flavonols in plants as stress protectors. According to Nakabayashi, Yonekura-Sakakibara, the increased production of flavonoids reduced the accumulation of $\mathrm{H}_{2} \mathrm{O}_{2}$ and exhibited enhanced oxidative and drought tolerance (47). A study by $\mathrm{Zhu}$, Li suggested that anthocyanins, a flavonoid class, acted as a secondary ROS scavenger in sugarcane leaves under chilling stress, that compensated the ineffective activity of antioxidant enzymes and contributed to chilling tolerance (49). These evidences suggest that flavonoids have a protective role during stress, and different species have specific molecular mechanisms to synthesize a variety of secondary metabolites to cope with the impact of stress.

Correlation coefficient (r) analysis between the TFC and the DPPH free radical scavenging activity $\left(\mathrm{IC}_{50}\right.$ values) of E. sonchifolia extracts was determined using the data from triplicate experiments. According to data analysis using SPSS, it was found that there was a negative significant correlation between TFC and antioxidant activity of E. sonchifolia extracts $\left(\mathrm{IC}_{50}\right)(\mathrm{r}=-0.998, \mathrm{P}<0.01)$. The negative correlation coefficient indicated that the lower the value of DPPH $\left(\mathrm{IC}_{50}\right)$, the higher the TFC. The data suggested that flavonoids had a stronger influence on the antioxidant activity of $E$. sonchifolia extracts. In conclusion, heat and water stress has a higher impact on the radical scavenging activity of $E$. sonchifolia which eventually leads to the increased antioxidant activity. As the stress level increases, the oxidative stress in plant tissues is elevated causing peroxidation of lipids. The increment of the antioxidant levels is attributed to their higher radical scavenging ability, which can prevent oxidative stress due to the presence of bioactive flavonol metabolites.

Factors such as the severity of stress, the time duration of exposure and the type of species should be taken into consideration. In a study by Guo, He on Scaevola aemula, it was shown that with short time high-temperature stress of $46{ }^{\circ} \mathrm{C}$ for 6 hours in a day, the biosynthesis of photosynthetic pigments chlorophyll and carotenoid in the leaves increased (50). However, the prolonged hightemperature intensity in the subsequent two days resulted in the denaturation of the biosynthetic process of pigments and caused a further decrease in soluble protein content. In contrast, moderate and short-term deliberate stresses proved to be effective without much reduction in the biomass and thereby increasing product quality (51). The results from this study showed that following the severe short-term temperature stress and extended moderate drought stress (as the severity of stress was moderate in plants), serious leaf injuries were not visible in plants under study. Also, it is understood that the removal of elicitation treatment before the onset of the appearance of wilt would be advantageous for the increased production of flavonol metabolites without much injury to the plant.

Furthermore, the glycosylated flavonol production was prominent in analysed medicinal plant E. sonchifolia, which warrants future analysis looking for more glycosylated compounds in this medicinal plant. The LCMS/MS could be a better option for identification and structural characterization of glycosylated compounds, as it can ionize polar compounds readily. Various pharmacological studies revealed the potent antioxidant and anticancer effects of flavonoids present in E. sonchifolia $(52,53)$. Another study suggests that the flavonoids present in E. sonchifolia extracts can modulate lens opacification and oxidative stress in selenite-induced cataract (54). Furthermore, Maikaeo, Chotigeat reported that E. sonchifolia leaf extracts, when fed to shrimp, acted as immunostimulants that protect them against virus (white spot syndrome virus and yellow head virus) induced diseases (55). The bioactive metabolites in E. sonchifolia had significantly high biological activities and in the future, the plant can be actively used in preclinical, clinical andtherapeutic trials investigating new treatments of diseases.

\section{Conclusions}

Elicitation through short-term heat stress and moderate

Table 2. Total flavonoid concentration in E. sonchifolia plants

\begin{tabular}{|c|c|}
\hline \multirow{2}{*}{ Treatment } & $\begin{array}{c}\text { Total flavonoid Concentration } \\
\text { (mgREg-1DW) }\end{array}$ \\
\cline { 2 - 2 } & E. sonchifolia \\
\hline Control & $3.52 \pm 0.84$ \\
\hline Heat & $8.66 \pm 0.73^{*}$ \\
\hline Drought & $6.01 \pm 0.85^{*}$ \\
\hline
\end{tabular}

Data was represented as mean \pm standard deviation of triplicate experiments. The treated samples with single asterisk $\left(^{*}\right)$ adhered indicate $\mathrm{P}<0.05$ and were statistically significant from control as determined by Dunnett's test. 
Table 3. $I C_{50}$ values of $E$. sonchifolia extracts

\begin{tabular}{|c|c|}
\hline \multirow{2}{*}{ Treatment } & IC50 values $\left(\boldsymbol{\mu g m \mathbf { ~ I } ^ { - 1 } )}\right.$ \\
\cline { 2 - 2 } & E. sonchifolia \\
\hline Control & 46.9 \\
\hline Heat & $40.6^{*}$ \\
\hline Drought & $42.6^{*}$ \\
\hline
\end{tabular}

The $I_{50}$ values of the plant extract, as shown above, were calculated from Figure 9. The control and treated samples were statistically significant $(P<0.05)$ as determined by Dunnett's test indicated by an asterisk $\left(^{*}\right)$.

water deficit stress proved to be an effective strategy to enhance the production of flavonols including rutin, quercetin and kaempferol in medicinal plants, well known for their potential benefits in therapeutic and nutraceutical industries. The results from this study inferred E. sonchifolia as a promising source of natural antioxidants. With reference to various pharmacological studies, it could be used for the development of natural product-based therapies against cataract as well as in the treatment of cancer. The water deficit results suggest that, non-severe or moderate stress applied before the harvest of medicinal plants can induce a significant increase in secondary metabolites without detriment to biomass accumulation. However, each plant species responds to stress differently. Consequently, further research is needed to optimise metabolic production in each species before applying these simple methods.

\section{Acknowledgements}

Authors thank the core funding from National Institute of Education, Nanyang Technological University Singapore to Z.C.

\section{Conflict of interest}

Authors declare that there are no conflicts of interest.

\section{References}

1. Davies KM, Deroles SC. Prospects for the use of plant cell cultures in food biotechnology. Curr Opin Biotechnol. 2014;26:133-40.

2. Sathuluri RR, Gokare R. Vanilla flavour: production by conventional and biotechnological routes. J. Sci. Food Agric. 2000;80:289-304

3. Wink M. Modes of action of herbal medicines and plant secondary metabolites. Medicines (Basel, Switzerland). 2015;2(3):251-86.

4. Lee LK, Foo KY. Recent advances on the beneficial use and health implications of Pu-Erh tea. Food Research International. 2013;53(2):619-28.

5. Frederick Hill A. Economic botany: a textbook of useful plants and plant products. Science. 1939;89(2309):294.

6. Nguyen $\mathrm{NH}, \mathrm{Kim} \mathrm{JH}$, Kwon J, Jeong CY, Lee W, Lee D, et al. Characterization of Arabidopsis thaliana FLAVONOL SYNTHASE 1 (FLS1) -overexpression plants in response to abiotic stress. Plant Physiol Biochem. 2016;103:133-42.

7. Sultana B, Anwar F. Flavonols (kaempeferol, quercetin myricetin) contents of selected fruits, vegetables and medicinal plants. Food Chem. 2008;108(3):879-84.

8. Perez-Vizcaino F, Fraga CG. Research trends in flavonoids and health. Arch Biochem Biophys. 2018;646:107-12.

9. Javed $H$, Khan MM, Ahmad A, Vaibhav K, Ahmad ME,
Khan $A$, et al. Rutin prevents cognitive impairments by ameliorating oxidative stress and neuroinflammation in rat model of sporadic dementia of Alzheimer type. Neuroscience. 2012;210:340-52.

10. Li, Yao J, Han C, Yang J, Chaudhry MT, Wang S, et al. Quercetin, inflammation and immunity. Nutrients. 2016;8(3):167.

11. Anand David AV, Arulmoli R, Parasuraman S. Overviews of biological importance of quercetin: a bioactive flavonoid. Pharmacogn Rev. 2016;10(20):84-9.

12. Kim JK, Park SU. Quercetin and its role in biological functions: an updated review. EXCLI J. 2018;17:856-63.

13. Choi JH, Park SE, Kim SJ, Kim S. Kaempferol inhibits thrombosis and platelet activation. Biochimie. 2015;115:177-86.

14. Winkel-Shirley B. Biosynthesis of flavonoids and effects of stress. Curr Opin Plant Biol. 2002;5(3):218-23.

15. Saito K, Yonekura-Sakakibara K, Nakabayashi R, Higashi Y, Yamazaki M, Tohge T, et al. The flavonoid biosynthetic pathway in Arabidopsis: structural and genetic diversity. Plant Physiol Biochem. 2013;72:21-34.

16. Oksman-Caldentey, Kirsi-Marja, Inzé D. Plant cell factories in the post-genomic era: new ways to produce designer secondary metabolites. Trends Plant Sci. 2004;9(9):433-40.

17. Yang L, Wen K-S, Ruan X, Zhao Y-X, Wei F, Wang Q. Response of plant secondary metabolites to environmental factors. Molecules (Basel, Switzerland). 2018;23(4):762.

18. Gorelick J, Bernstein N. Chapter Five - Elicitation: an underutilized tool in the development of medicinal plants as a source of therapeutic secondary metabolites. In: Sparks DL, editor. Advances in Agronomy. 124: Academic Press; 2014. p. 201-30.

19. Ramakrishna A, Ravishankar GA. Influence of abiotic stress signals on secondary metabolites in plants. Plant Signal Behav. 2011;6(11):1720-31

20. Shen SM, Shen LG, Lei QF, Si JY, Liu CM, Lu H. Chemical constituents contained in aerial parts of Emilia sonchifolia. Zhongguo Zhong Yao Za Zhi. 2012;37(21):3249-51.

21. Dash G, Syafiq Abdullah M, Yahaya R. Traditional uses, phytochemical and pharmacological aspects of Emilia sonchifolia (L.) Int J Res Ayurveda Pharm. 2015;6(4):551-556.

22. Arun Raj G, Shailaja U, Rao PN, Sharanesh T, Gokul J. Review on the contribution of Dashapushpa: a traditional medicine in the management of cancer. Global J Res Med Plants \& Indigen Med. 2013;2(9):656-63.

23. Muko KN, Ohiri FC. A preliminary study on the antiinflammatory properties of Emilia sonchifolia leaf extracts. Fitoterapia. 2000;71(1):65-8.

24. Lija Y, Biju PG, Reeni A, Cibin TR, Sahasranamam V, Abraham A. Modulation of selenite cataract by the flavonoid fraction of Emilia sonchifolia in experimental animal models. Phytother Res. 2006;20(12):1091-5.

25. Sophia D, Ragavendran P, Arulraj C, Gopalakrishnan VK. In vitro antioxidant activity and HPTLC determination of n-hexane extract of Emilia sonchifolia (L.)DC. J Basic Clin Pharm. 2011;2(4):179-83.

26. Mamta R. Natural antioxidant (flavone glycoside) from Emilia sonchifolia DC. and its potential activity. Int J Pharm Pharm Sci. 2012;4:159-162.

27. Maikaeo L, Chotigeat W. Emilia sonchifolia extract activity against white spot syndrome virus and yellow head virus in shrimp cell cultures. Dis Aquat Organ. 2015;115(2):157-64.

28. Nasrollahi V, Mirzaie-asl A, Piri K, Nazeri S, Mehrabi R. The effect of drought stress on the expression of key genes involved in the biosynthesis of triterpenoid saponins in liquorice (Glycyrrhiza glabra). Phytochemistry. 2014;103:32-7.

29. Daudi A, O'Brien JA. Detection of hydrogen peroxide by DAB staining in arabidopsis leaves. Bio Protoc. 2012;2(18):e263.

30. Neves NdA, Stringheta PC, Gómez-Alonso S, HermosínGutiérrez I. Flavonols and ellagic acid derivatives in peels of different species of jabuticaba (Plinia spp.) identified by HPLC-DAD-ESI/MSn. Food Chem. 2018;252:61-71. 
31. Pękal A, Pyrzynska K. Evaluation of aluminium complexation reaction for flavonoid content assay. Food Anal Methods. 2014;7(9):1776-82.

32. Zhang, Cao Z, Xie Z, Lang D, Zhou L, Chu Y, et al. Effect of water stress on roots biomass and secondary metabolites in the medicinal plant Stellaria dichotoma L. var. lanceolata Bge. Sci Hortic. 2017;224:280-5.

33. Gai Q-Y, Jiao J, Luo M, Wei Z-F, Zu Y-G, Ma W, et al. Establishment of hairy root cultures by agrobacterium rhizogenes mediated transformation of Isatis Tinctoria L. for the efficient production of flavonoids and evaluation of antioxidant activities. PLoS One. 2015;10(3):e0119022.

34. Matteini P, Agati G, Pinelli P, Goti A. Modes of complexation of rutin with the flavonoid reagent diphenylborinic acid 2-aminoethyl ester. Monatsh Chem. 2011;142:885.

35. Cen M, Ruan J, Huang L, Zhang Z, Yu N, Zhang Y, et al Simultaneous determination of thirteen flavonoids from Xiaobuxin-Tang extract using high-performance liquid chromatography coupled with electrospray ionization mass spectrometry. J Pharm Biomed Anal. 2015;115:214-24.

36. Li Z, Guo H, Xu WB, Ge J, Li X, Alimu M, et al. Rapid identification of flavonoid constituents directly from PTP1B inhibitive extract of raspberry (Rubus idaeus L.) leaves by HPLC-ESI-QTOF-MS-MS. J Chromatogr Sci. 2016;54(5):805-10.

37. Chen G, Li X, Saleri F, Guo M. Analysis of flavonoids in Rhamnus davurica and its antiproliferative activities. Molecules (Basel, Switzerland). 2016;21(10).

38. Kirakosyan A, Kaufman P, Warber S, Zick S, Aaronson K, Bolling $S$, et al. Applied environmental stresses to enhance the levels of polyphenolics in leaves of hawthorn plants. Physiol Plant. 2004;121(2):182-6.

39. Hodaei M, Rahimmalek M, Arzani A, Talebi M. The effect of water stress on phytochemical accumulation, bioactive compounds and expression of key genes involved in flavonoid biosynthesis in Chrysanthemum morifolium L. Ind Crops Prod. 2018;120:295-304.

40. Xiaolu W, Jie Y, Aoxue L, Yu C, Yijun F. Drought stress and re-watering increase secondary metabolites and enzyme activity in dendrobium moniliforme. Ind Crops Prod. 2016:94:385-93.

41. Barton KE, Koricheva J. The ontogeny of plant defense and herbivory: characterizing general patterns using metaanalysis. Am Nat. 2010;175(4):481-93.

42. Agati G, Azzarello E, Pollastri S, Tattini M. Flavonoids as antioxidants in plants: location and functional significance. Plant Sci. 2012;196:67-76.

43. Nacif de Abreu I, Mazzafera P. Effect of water and temperature stress on the content of active constituents of Hypericum brasiliense Choisy. Plant Physiol Biochem. 2005;43(3):241-8.

44. Le Roy J, Huss B, Creach A, Hawkins S, Neutelings G. Glycosylation is a major regulator of phenylpropanoid availability and biological activity in plants. Front Plant Sci. 2016;7(735)

45. Hectors K, Van Oevelen S, Geuns J, Guisez Y, Jansen MA, Prinsen E. Dynamic changes in plant secondary metabolites during UV acclimation in Arabidopsis thaliana. Physiol Plant. 2014;152(2):219-30.

46. Selmar D, Kleinwächter M. Influencing the product quality by deliberately applying drought stress during the cultivation of medicinal plants. Ind Crops Prod.2013;42:558-66.

47. Nakabayashi R, Yonekura-Sakakibara K, Urano K, Suzuki M, Yamada Y, Nishizawa T, et al. Enhancement of oxidative and drought tolerance in Arabidopsis by overaccumulation of antioxidant flavonoids. Plant J. 2014;77(3):367-79

48. Fini A, Guidi L, Ferrini F, Brunetti C, Di Ferdinando M, Biricolti $S$, et al. Drought stress has contrasting effects on antioxidant enzymes activity and phenylpropanoid biosynthesis in Fraxinus ornus leaves: an excess light stress affair? J Plant Physiol. 2012;169(10):929-39.

49. Zhu J-J, Li Y-R, Liao J-X. Involvement of anthocyanins in the resistance to chilling-induced oxidative stress in Saccharum officinarum L. leaves. Plant Physiol Biochem. 2013;73:427-33.

50. Guo T, He B, Huang H, Xi W, Chen X. Physiological responses of Scaevola aemula seedlings under high temperature stress. S Afr J Bot. 2017;112:203-9.

51. Nowak M, Kleinwächter $M$, Manderscheid $R$, Weigel HJ, Selmar D. Drought stress increases the accumulation of monoterpenes in sage (Salvia officinalis), an effect that is compensated by elevated carbon dioxide concentration. J Appl Bot Food Qual. 2010;83(2):133-6.

52. Devi D G, Y L, Raghavan C, Biju P, Devi V, Annie A Evaluation of the protective effects of Emilia sonchifolia Linn. (DC.) on perchlorate-induced oxidative damage. J Biol Sci. 2006;6.

53. Raghavan C, Gopala S, Devi D G, Srinivas P, Y L, Annie A Antioxidant and antiproliferative effects of flavonoids from Emilia sonchifolia Linn on human cancer cells. International Journal of Pharmacology. 2006;2.

54. Lija Y, Biju P, Reeni A, Raghavan C, Sahasranamam V, Abraham A. Modulation of selenite cataract by the flavonoid fraction of Emilia sonchifolia in experimental animal models. Phytother Res. 2006;20:1091-5.

55. Maikaeo L, Chotigeat W, Mahabusarakam W. Emilia sonchifolia extract activity against white spot syndrome virus and yellow head virus in shrimp cell cultures. Dis Aquat Organ. 2015;115(2):157-64. 